Journal of Education and Educational Development

7(2), 307-327, 2020

DOI: http://dx.doi.org/10.22555/joeed.v7i2.31

\title{
Technology Integration and Teachers' Professional Knowledge with Reference to International Society for Technology in Education (ISTE)-Standard: A Causal Study
}

\author{
Rabia Aslam \\ rabee_malik@hotmail.com
}

Shaheed Zulfikar Ali Bhutto Institute of Science and Technology, Pakistan

Najmonnisa Khan

najmunnisa7@hotmail.com

Shaheed Zulfikar Ali Bhutto Institute of Science and Technology, Pakistan

\author{
Ushaque Ahmed \\ saniushaque@gmail.com
}

Shaheed Zulfikar Ali Bhutto Institute of Science and Technology, Pakistan

\begin{abstract}
It is becoming a new trend in developing countries to integrate ICT effectively in the teaching-learning process inside or outside the classroom to boost teachers' professional knowledge (TPK). The present study addresses the technology integration relationship with TPK according to the International Society for Technology in Education (ISTE-2008) Standards for Teachers in private secondary schools of Karachi. TPK was categorized as 2 standards of ISTE-2008 i.e. enhance creativity in students and design digital-age assessment. 120 teachers from 12 private secondary schools of Karachi were selected based on a simple random sampling technique. For the collection of data, a teacher survey questionnaire was used that was designed to gain information on their level of ICT integration and their professional knowledge according to the ISTE-2008 Standards. Data was collected through questionnaire distribution and analyzed through SPSS. Based on ANOVA results, the overall model was significant because the $F$ value was greater than 2 and the significant value was less than 0.05. A strong significant correlation
\end{abstract}


was found between ICT integration and TPK. Strong and moderate significant correlation of ICT integration with teachers' ability to enhance creativity and design digital-age assessment was found respectively. ICT integration explained $32 \%$ of the variance in teachers' professional knowledge. The integration of ICT with ISTE-standards is highly recommended for the teachers.

Keywords: creativity, digital-age assessment, ISTE, teachers' professional knowledge, technology integration

\section{Introduction}

Currently, society is stratified and unequal with regards to media and digital literacy; communication skills and critical thinking essential to evaluate information; a knowledge, and an information gap; participatory inequalities and collaboration (Radovanovic, 2011). Educators need to be knowledgeable and have an understanding of the significance of developing 21 st-century skills, including information and communications technology (ICT) literacy to assist in focusing these inequalities in the schools (Warschauer \& Ware, 2008).

The International Society for Technology in Education (ISTE) is working as a non-profit institute that is striving toward providing technology-related standards for teachers, learners, coaches, administrators and educators. Furthermore, ISTE provides technology conferences for educators. The ISTE-2008 Standards for teachers, which is also known as the National Education Technology Standards (NETS), are recognized and adopted throughout the world. They are used for twenty-first-century learning and teaching, setting a standard of excellence by incorporating technology and effective learning practices (Garcia, 2018; Sam, 2011).

ICTs effectiveness has been accepted worldwide to develop quality education. Teachers who are effectively integrating ICT in the teaching \& learning process are considered as a core element in education (Agostinho et al., 2002). Therefore, teachers themselves must be very competent and confident in using ICT. The data received from the findings of Khokhar and Javaid (2016) showed that $95 \%$ of teachers of Pakistan have access to ICT devices in school or at their home. According to Garcia (2018), the ISTE Standards used for Teachers are the set 
standard criteria used throughout the world to assess the knowledge \& skills that teachers need to communicate, work on, \& acquire in the twenty-first century, which helps them to enhance their professional knowledge.

This study was conducted to determine the extent to which individual teachers in a private secondary school were using technology as a tool for their students' education. In particular, the research addresses the use of technology by teachers as a classroom tool to enhance student creativity and to design digital-age assessment as outlined by the National Technology Standards (i.e. ISTE-standards) for teachers. Analyses include the effect of ICT integration on teachers' professional knowledge concerning ISTE-standards. The results of this study can be used to structure; in-service training programs related to ISTE-standards, pre-service education curricula, and interventions for individual teachers. The study scope was limited to the Karachi region as it was easier logistically for the researcher to research the local scenario.

\section{Research Questions}

1. What is the existing status of teachers to integrate ICT in teaching at the secondary level in private schools?

2. Is there any significant relationship between ICT integration and teachers' professional knowledge concerning ISTE-2008 standards?

2.1. Is there any significant relationship between ICT integration and teachers' ability to enhance creativity in students?

2.2. Is there any significant relationship between ICT integration and teachers' ability to design a digital-age assessment?

\section{Literature Review}

\section{Technology Acceptance in a Digital-age}

Usage of the term Digital-age is very common for authors in the current period of education (Brown, 2013; Garcia, 2018). It is not far when the computer will become ubiquitous in schools and homes, and different varieties of terminologies will be used like the internet era, people at large will use information era, knowledge and the digital era commonly. The ISTE-2008, International Society for Technology in Education, is aimed at advancing the effective use of standard technology for students, teachers, instructional coaches, and 
administrators, and refers to the current education period as digital-age. Because it is seen as shifting the learning culture from teaching based and individual learning to a participatory learning model (Education, 2010a; Kaplan \& Owings,2013). Additionally, the digital era in education is boosting and shifting a learning culture from an instruction based or individualistic model of learning towards learning based on a hands-on model of learning. A well-known philosopher Brown (2013), in wisdom culture, stated that "the primary difference between the teaching-based approach to education and the learning-based approach is that in the first case the culture is the environment, while in the second case, the culture emerges from the environment - and grows along with it" (p. 15).

\section{Teachers Professional Knowledge}

During recent years teacher's knowledge is being researched on the principle of differentiation between their knowledge of content, pedagogical content knowledge, and general pedagogical knowledge because it contributes to the actual learning and coaching of learners \& their learning (Blömeke \& Delaney, 2012; Dogan et al., 2016; König, 2014). Teacher knowledge supports evidence that subject related specific skills \& knowledge on the instructor aspects are significant elements for the accomplishment of their learners (Baumert et al., 2010; Dogan et al., 2016; Hill et al., 2005; Sadler et al., 2013). Teacher's educational effectiveness needs to be researched. Moreover, it is very important to measure teacher's knowledge as a product outcome at numerous phases of teachers' overall education (König \& Kramer,2016). The knowledge of teachers makes a substantial difference in the involvement towards real teaching \& learner's learning is widely accepted (Darling-Hammond \& Baratz-Snowden, 2007; Dogan et al., 2016; Gitomer et al., 2015; Grossman \& McDonald, 2008). Teachers' specific subject-based knowledge $\&$ skills determine the progress of students. The research follows the leading work of Shulman (1986 \& 1987), researches have proved the significance of assessing teachers' knowledge as a consequence of effective teaching and learning. The idea of classifying teachers' knowledge is widely accepted. Categories include content knowledge (CK), general pedagogical knowledge (GPK), and pedagogical content knowledge (PGK) (König \& Kramer, 2016).

\section{Technology Acceptance Theories and Models}

Theories provide explanations that can be used to expect specific 
phenomena. While the model is expressed as the logical explanation of a structure, a phenomenon, or a theory, constructed to understand, represent, predict, or to control the phenomena which are being inspected. For the use and acceptance of the technologies environment, a vast number of models and theories have been designed (Burch, 2003; Samaradiwakara \& Gunawardena, 2014).

Technology Acceptance Model (TAM-1) mentions psychological factors affecting technology acceptance, developed from the Theory of Reasoned Action by Davis (1989). It posits that perceived usefulness and ease of use determine one's attention to use a system (Straub, 2009). TAM 2 is a theoretical extension, which leads to TAM-1- including supplementary factors of TAM explaining perceived usefulness regarding social influence and cognitive processes and to understand the changing effect of the determinants with increased experience of user overtime. According to this model, both social influence processes and cognitive instrumental processes influence user acceptance (Kriponanat, 2007; Straub, 2009; Venkatesh \& Davis, 2000).

\section{Technology Integration and Teachers' Professional Knowledge}

Guma et al. (2013) revealed that the innovations brought about by ICT including e-learning, quick access to information, online registration, and reduced hardcopies, is a new trend in learning, used and integrated effectively by teaching staff as it has an impact on teacher's professional knowledge. It has chances of enhancing the integration of the teaching-learning process with ICT. ICT applications bring improvement in quality teaching and also in a subject which is under learning (Jamil et al., 2017). According to Hennessy et al. (2010), the use of ICT and pedagogical implications for the professional development of teachers brings schooling within the developmental context in the technological century. There has been a huge emphasis and working on employing ICT for academic purposes in Pakistan especially from the elementary level in Punjab (Ali et al., 2015; Iqbal et al., 2015).

The accreditation process is considered an effective measure to process guidance and mechanisms to assure quality education as being pivotal for national development much like economic \& socio-cultural advancement for a state. To achieve the above purpose an authority was established namely 'National 
Accreditation Council for Teacher Education, NACTE' (Policy and Planning Wing, 2009; National Accreditation Council for Teacher Education, 2009). Pakistan Ministry of education developed 'National Professional Standards for Teachers in Pakistan' with the collaboration of UNESCO and USAID, a guideline for teacher educators. Standard 7 focuses on ICT and suggests teacher educators furnish tutors with skills to use hardware and software technologies (Huma, 2013).

Teachers' professional knowledge (TPK) depends on how effectively the teacher is incorporating digital tools in their teaching and guiding students towards the digital job market (Garcia, 2018; Sam, 2011). The ISTE-2008 standards, are standards used for teachers to assess their teaching process. The teacher must incorporate ISTE Standards to not only assess their professional knowledge but also to prepare students for the digital age. The ISTE Standards for Teachers include facilitating and inspiring student learning and creativity, designing digital-age assessment and learning experience, modeling digital-age learning, promoting digital citizenship and responsibility, and engaging leadership (ISTE, 2008). The present study focused only on the first two standards of ISTE-2008.

\section{Technology Role in Learning \& Creativity}

Education technology including e-learning, use of mobile devices, and smartphone Apps has become more flexible and available and contributes to the improvement in student's learning. Electronic based learning system and Web-based instructions have been widely accepted as stimuli for inducing creativity and enhancing brainstorming capabilities by making things perceived in new and unfamiliar ways by students, which is increased through technology (Chang, 2001; Cropley, \& Cropley, 2016; Jang, 2019; Jonassen, 2000; Keengwe, 2015; Nath, 2019).

\section{Technology Role in Assessment}

Technology covers almost all areas of society. In Education, two trends can be seen: first is digital competency in assessment and curricula, and the second, teachers are encouraged to integrate technology in their teaching as a useful tool to facilitate learners for formative assessment (Scherer et al., 2019). Technologically enhanced especially Internet-based formative assessment tools support teachers to easily collect and analyze the data in student assessment and make instructional 
decisions based on that data (Martin et al., 2016). Technology eases the process of data analysis for a teacher. The use of technology in student assessment is affected by the school culture and the amount of support given for the technology-based assessment for a teacher (Oldfield et al., 2012; Whitelock et al., 2008). Technology has been employed greatly in the educational sector to enable the process of assessment and response to assessment challenges. Technology-Enhanced Assessment TEA or digital technologies could significantly change assessment through multiple types of assessments to treat summative assessment, capturing various skills such as peer interaction and the use of data analytics to inform assessment practices (Sweeney et al., 2017; Whitelock et al., 2011).

\section{Conceptual Framework}

In the present study, ICT integration was used as an independent variable and teachers' professional knowledge was the dependent variable. Teachers' professional knowledge (TPK) was further categorized as two sub-variables which included; teachers' ability to enhance creativity in students' and teachers' ability to design digital-age assessment. These variables were compiled to present the conceptual framework for the study (see Figure 1).

\section{Figure 1}

The Conceptual Framework for the Study

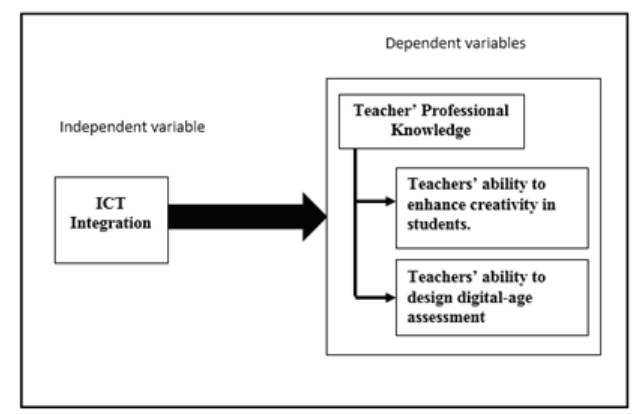

\section{Methodology}

The purpose of this quantitative study was to examine the relationship between technology integration and teachers' professional knowledge concerning ISTE-2008 standards. A survey research design was utilized in this study. Teachers of all Private secondary schools of Karachi were included as the research 
population. A multi-stage sampling technique was applied for the present study. The researcher employed a survey procedure to collect data that was quantitatively analyzed.

Karachi is divided into 6 districts which are District West, District Malir, District Central, District Korangi, District East and District South. In the first stage, 2 private secondary schools from each district of Karachi region were chosen based on cluster random sampling technique then 10 teachers from each school were selected by using a simple random sampling technique so, the overall sample was comprised of 120 private secondary school teachers.

Data was collected from the personal visit. A teacher survey questionnaire was used for data collection. The questionnaire comprised of three sections. Demographic information such as gender, educational background, teaching experience, staff development training was included in section I. Section II was about ICT integration in teaching, consisting of 23 items based on a five-point Likert scale. Section III items were about teachers' professional knowledge. TPK consisted of 2 standards of ISTE-2008 (adopted from Sam, 2011). These standards were based on teachers' ability to enhance creativity in students' and teachers' ability to design digital-age assessment to obtain information on teachers' level of professional knowledge. Each standard consisted of 4 items based on a five-point Likert scale.

Professionals in educational technology established the validity of the instrument for this study, by allowing them to review the instrument. The reliability of the instrument was established with Cronbach's Coefficient of reliability of 0.906. Table 1 displays the reliability of the instrument.

Furthermore, data were analyzed using SPSS. Descriptive statistics were used to find to what extent teachers' are integrating ICT in their teaching while correlation analysis by using SPSS was done to find the relation of ICT integration and teacher's ability to enhance creativity in students and design digital-age assessment. Linear regression was run to find the effect of technology integration on teachers' professional knowledge. 


\section{Table 1}

Alpha Reliability

\begin{tabular}{|c|c|c|c|}
\hline S.No & Domain & No of Items & Alpha reliability \\
\hline 1 & Technology Integration in Teaching & 23 & 0.864 \\
\hline 2 & Teachers' ability to enhance creativity in students. & 4 & 0.874 \\
\hline 3 & Teachers' ability to design digital-age assessments & 4 & 0.910 \\
\hline 4 & Total & 31 & 0.906 \\
\hline
\end{tabular}

\section{Findings}

\section{Existing Status of Teachers to Integrate ICT in Teaching}

The first research question of this study focused on the existing status of teachers to integrate ICT in teaching at the secondary level in private schools of Karachi. Descriptive statistics were used for this purpose to find the application of social media, documentation tools, and computer hardware in the teaching process.

\section{ICT integrated Social Media used in Support of Classroom Teaching}

\section{Table 2}

ICT integrated Social Media used in Support of Classroom Teaching

\begin{tabular}{lccc}
\hline & N Valid & Mean & SD \\
\hline Facebook & 120 & 1.78 & 1.156 \\
Twitter & 120 & 1.52 & .788 \\
Email & 120 & 3.64 & 1.608 \\
Social Bookmarking & 120 & 1.98 & 1.429 \\
Wikipedia & 120 & 2.14 & 1.491 \\
Blogger & 120 & 1.74 & 1.220 \\
Google Doc & 120 & 3.59 & 1.580 \\
\hline
\end{tabular}

Table 2 represents descriptive statistics of participants' responses in terms of ICT integrated social media which they were using in classroom teaching. Figure 2 represents the most common ICT integrated social media used to support classroom teaching were Email and Google Document with a Mean of 3.64 and 
3.59 respectively. The least common ICT integrated social media is Twitter with a Mean value of 1.52 .

Figure 2

ICT integrated Social Media used in Support of Classroom Teaching

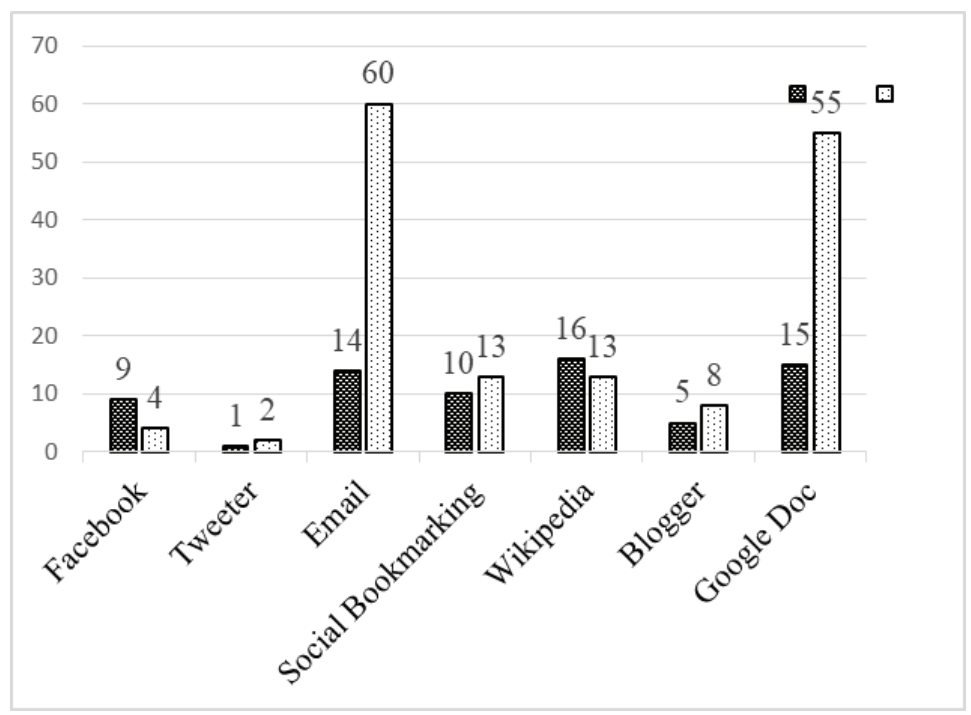

ICT integrated Documentation tools used in support of classroom teaching

\section{Table 3}

ICT integrated Documentation tools used in Support of Classroom Teaching

\begin{tabular}{lccc}
\hline & N Valid & Mean & SD \\
\hline MS Office Word & 120 & 3.82 & 1.506 \\
MS Office Excel & 120 & 3.38 & 1.661 \\
MS Office PowerPoint & 120 & 3.70 & 1.464 \\
MS Office Publisher & 120 & 1.55 & 1.028 \\
MS Office Access & 120 & 1.48 & .987 \\
MS Office Groove & 120 & 1.33 & .890 \\
MS Office InfoPath & 120 & 1.41 & .884 \\
MS Office OneNote & 120 & 1.65 & 1.082 \\
MS Office Outlook & 120 & 2.39 & 1.190 \\
\hline
\end{tabular}


Table 3 represents descriptive statistics of participants' responses in terms of the ICT integrated documentation tool which they were using in classroom teaching. Figure 3 represents the most common ICT integrated documentation tools used to support classroom teaching was MS PowerPoint, MS Office Word, and MS Excel with a Mean value of 3.82, 3.38, and 3.70 respectively. The least common ICT integrated documentation tool is the MS Info path with the Mean value of 1.41.

\section{Figure 3}

ICT integrated Social Media used in Support of Classroom Teaching

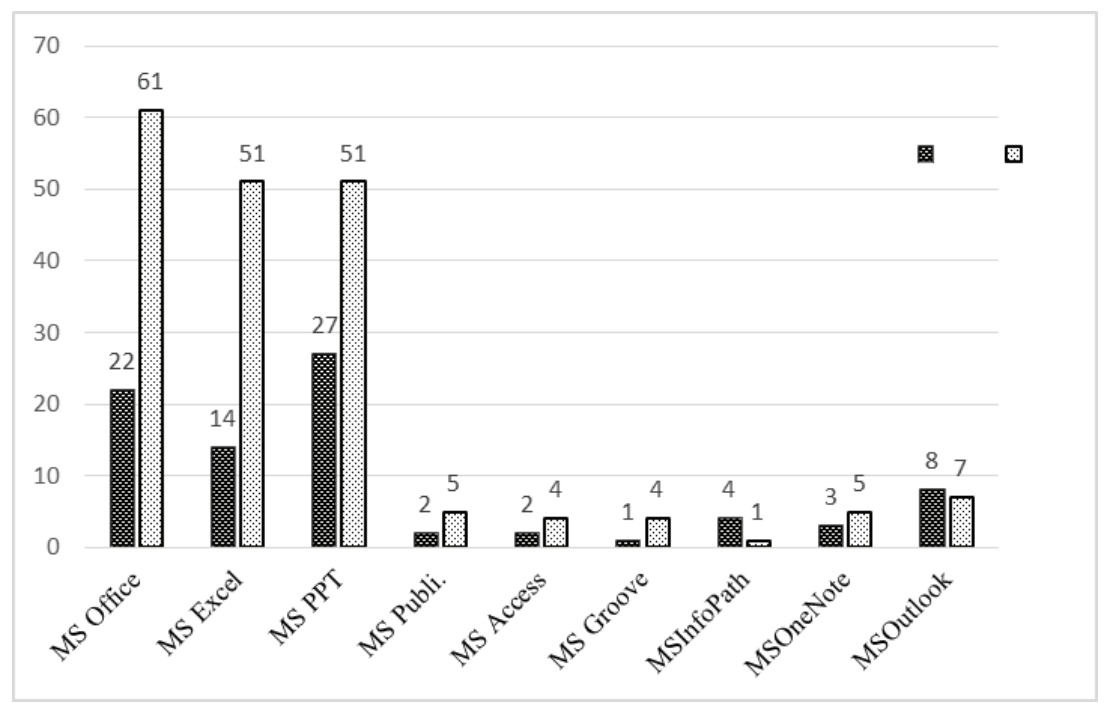

\section{ICT Integrated Computer Hardware used in support of classroom teaching}

Table 4 represents descriptive statistics of participants' responses in terms of ICT integrated hardware which they were using in classroom teaching. Figure 4 represents the most common ICT integrated hardware used to support classroom teaching was USB/ Flash Drive and Computer/ Laptop/ Tablets with Mean of 3.85, and 3.83 respectively. The least common ICT integrated hardware was CD Rom with a Mean value of 1.89 . 
Table 4

ICT Integrated Computer Hardware used in Support of Classroom Teaching

\begin{tabular}{lccc}
\hline & N Valid & Mean & SD \\
\hline LCD Projector & 120 & 3.35 & $1 / 543$ \\
Over Head Projector & 120 & 3.26 & 1.688 \\
Computer/ Laptop/ & 120 & 3.83 & 1.465 \\
Notebook/ Tablet & & & \\
CD Rom & 120 & 1.89 & 1.302 \\
Scanner/ Printer/ Xerox & 120 & 3.18 & 1.471 \\
Machine (3 in 1) & & & \\
TV/ VCD/ DVD & 120 & 2.43 & 1.333 \\
USB or Flash Drive & 120 & 3.85 & 1.482 \\
\hline
\end{tabular}

Figure 4

Hardware in Support Teaching Lesson

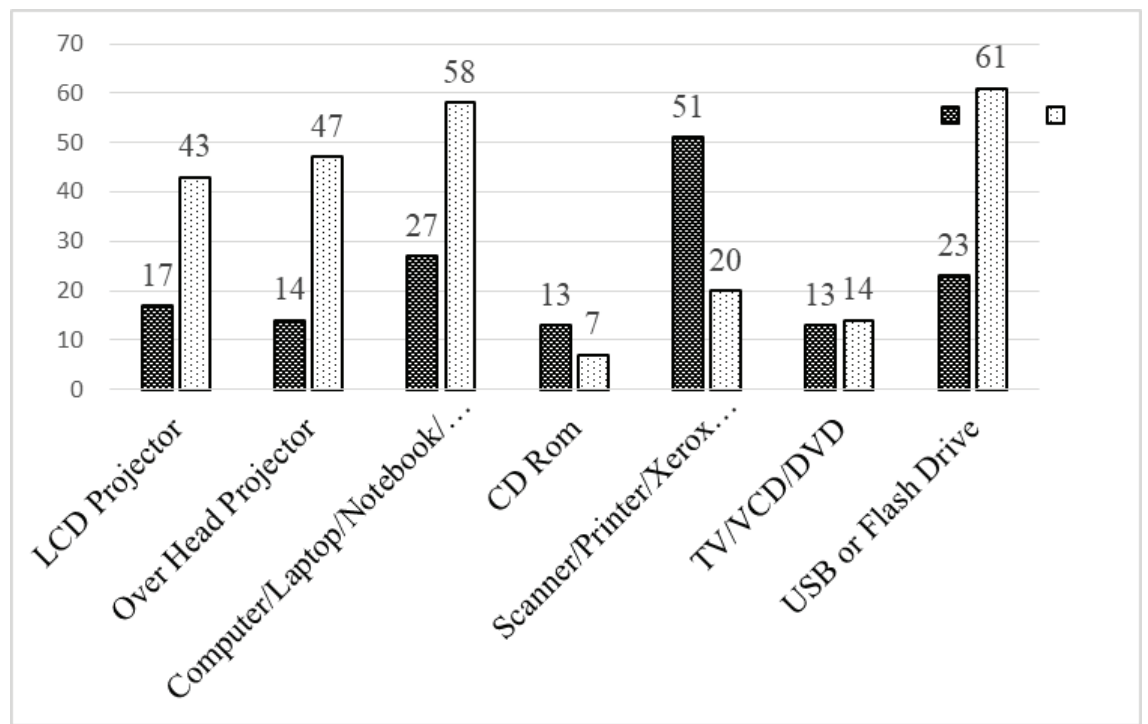

\section{Relationship of ICT integration with teachers' Professional Knowledge}

The second research question of this study was to find the relationship of ICT integration with Teachers' professional knowledge in terms of teachers' ability 
to enhance creativity in students and to design digital-age assessment. Since the responses exhibited normal distribution, the data were analyzed with a parametric test. The Pearson correlation coefficient was used to see whether TPK was significantly related to ICT integration or not.

\section{Table 5}

Correlation between ICT Integration and TPK

\begin{tabular}{llc}
\hline & & ICT Integration \\
Teachers' professional & Pearson Correlation & $.750^{* *}$ \\
knowledge. & $\mathrm{N}$. (2-tailed) & .000 \\
& $\mathrm{~N}$ & 120 \\
& & 120 \\
Facilitate and Inspire Student & Pearson Correlation & $.765^{* *}$ \\
Learning and Creativity & Sig. (2-tailed) & .000 \\
& $\mathrm{~N}$ & 120 \\
Design and Develop Digital- & Pearson Correlation & $.635^{* *}$ \\
Age Learning Experiences and & Sig. (2-tailed) & .000 \\
Assessments & $\mathrm{N}$ & 120 \\
\hline
\end{tabular}

** Correlation is significant at 0.05 level (2-tailed).

Table 5 shows the correlation between ICT integration and teachers' professional knowledge with its 2 sub-variables. Analysis of the sample found that ICT integration has a strong positive significant correlation with teachers' professional knowledge $(\mathrm{r}=.750, \mathrm{p}=.000)$. Strong, positive, significant correlation was found between ICT integration and TPK's 1st sub-variable i.e. teachers' ability to enhance creativity in students $(\mathrm{r}=.765, \mathrm{p}=.000)$. The correlation between the ICT integration and TPK's 2nd sub-variable i.e. teachers' ability to design digital-age assessment was also positive, significant but moderate $(\mathrm{r}=.635, \mathrm{p}=$ $.000)$. 


\section{Table 6}

Predictors of Teachers' Professional Knowledge

\begin{tabular}{clccccc}
\hline Model & \multicolumn{1}{c}{ Predictors } & $\mathrm{B}$ & Std. Error & Beta & $\mathrm{F}$ & $\mathrm{R}^{2}$ \\
\hline \multirow{2}{*}{1} & (Constant) & 2.169 & .234 & & & \\
& ICT Integration & .455 & .060 & .570 & 56.932 & $.325^{*}$
\end{tabular}

$* \mathrm{p}<.05$

Table 6 illustrated the result of linear regression analysis. Linear regression was applied with teachers' professional knowledge as a dependent variable and ICT integration as an independent variable. The independent variable ICT integration plays a significant role in explaining the dependent variable. ICT integration explained $32 \%$ of the variance in teachers' professional knowledge $(\mathrm{R} 2=.325)$, as measured by TPK. The overall model was found to be significant (F-statistics = 56.932 and Sig. $<0.050$ ).

In simple words, there is an impact of ICT integration on teachers' professional knowledge.

$\mathrm{Y}=\alpha+\beta_{1} \mathrm{X}_{1}+\varepsilon$

Teachers' Professional Knowledge $=\alpha+\beta 1$ (ICT integration) $+\varepsilon$

$\mathrm{TPK}=2.169+0.455(\mathrm{ICT}$ integration $)+\varepsilon$

If there is 1 unit change in ICT integration, there will be a 0.455 unit change in teachers' professional knowledge.

\section{Discussion}

Technology integration provides opportunities for teachers to enhance their professional knowledge. The study revealed the positive strong correlation of technology integration with teachers' professional knowledge. The result of linear regression analysis reported a statistically significant impact of ICT integration on teachers' professional knowledge. 
The finding of the first question indicates that secondary private school teachers of Karachi are most commonly integrating E-mail, Google Document, MS Office, MS PowerPoint, MS Excel, USB/ Flash Drive, and Computer/ Laptop/ Tablets in their teaching process. This finding supports the finding from the earlier study conducted by Khokhar and Javaid (2016).

The present study finding supports the finding that the teachers' ability to enhance creativity in students has a significant and positive relationship with ICT integration (Cropley \& Cropley, 2016; Jang, 2019; Jonassen, 2000; Keengwe, 2015). The positive correlation allows probability to create innovative techniques to enhance creativity in students (Chang, 2001). The more teacher will integrate ICT in teaching, the more creative students will be produced (Nath, 2019).

It also confirms that the teachers' ability to design digital-age assessment with ICT integration has a positive relationship (JISC, 2010; Scherer et al., 2019; Sweeney et al., 2017; Whitelock et al., 2011). Technologically enhanced especially Internet-based formative assessment tools support teachers to easily collect and analyze the data in student assessment and make instructional decisions based on that data (Martin et al., 2016).

Furthermore, the study identifies from the result of the second question that the overall model is significant and it confirms the study, which indicates that ICT integration has a significant effect on teachers' professional knowledge (Guma et al., 2013). The more teacher will integrate ICT in teaching, it will not only have an effect on students' achievement but also teachers themselves will be competent and their professional knowledge will increase (Ali et al., 2015; Iqbal et al., 2015).

\section{Conclusion \& Recommendations}

The study examined the impact of ICT integration on teachers' professional knowledge concerning ISTE-Standards for teachers in private secondary schools of Karachi. The professional knowledge of teachers was further categorized as teachers' ability to enhance creativity in students' and teachers' ability to design digital-age assessment. In light of the findings of the study, it can be concluded that ICT integration plays a vital role to enhance creativity in students and it also helps teachers to develop assessments that meet the criteria of the digital age of learning. Both of these factors directly impact teachers' professional knowledge regarding 
ISTE-standards when teachers integrate ICT in their teaching. As this era is called the technology advancement era, therefore it is highly recommended that teachers should be competent to integrate ICT in their teaching and for this government should provide sufficient funds to establish computer laboratories in schools and the responsibility of education minister should be to arrange training based on ISTE-standards for teachers to use ICT integration effectively in the teaching process. A follow-up plan should be developed for the implementation of ISTE-standards in teaching methodology.

\section{References}

Accreditation standards and procedures for quality assurance in teacher education in Pakistan. (2009). National Accreditation Council for Teacher Education: Islamabad.

Agostinho, S., Oliver, R., Harper, B., Hedberg, J., \& Wills, S. (2002). A tool to evaluate the potential for an ICT-based learning design to foster" high-quality learning". https://ro.uow.edu.au/edupapers/125

Ali, M. Q., Nargis, N., Yasmeen, R., \& Iqbal, Z. (2015). ICT use for effective teaching-learning process in secondary schools in Punjab province. Asian Journal of Social Sciences \& Humanities, 4(3), 138-143.

Barron, A. E., Kemker, K., Harmes, C., \& Kalaydjian, K. (2003). Large-scale research study on technology in $\mathrm{K}-12$ schools: Technology integration as it relates to the National Technology Standards. Journal of Research on Technology in Education, 35(4), 489-507.

Baumert, J., Kunter, M., Blum, W., Brunner, M., Voss, T., Jordan, A., \& Tsai, Y. M. (2010). Teachers' mathematical knowledge, cognitive activation in the classroom, and student progress. American Educational Research Journal, 47(1), 133-180.

Blömeke, S., \& Delaney, S. (2014). Assessment of teacher knowledge across countries: A review of the state of research. In International perspectives on teacher knowledge, beliefs and opportunities to learn (pp. 541-585). Springer.

Brown, B. (2013). How principals cultivate technology integration and use professional learning networks (Doctoral dissertation).

Burch, T. K. (2003). Demography in a new key: A theory of population theory. Demographic Research, 9, 263-284.

Chang, C. Y. (2001). Comparing the impacts of a problem-based computer-assisted 
instruction and the direct-interactive teaching method on student science achievement. Journal of Science Education and Technology, 10(2), 147-153.

Cropley, D., \& Cropley, A. (2016). Promoting creativity through assessment: A formative computer-assisted assessment tool for teachers. Educational Psychology, 56(6), 17-24.

Darling-Hammond, L., \& Baratz-Snowden, J. (2007). A good teacher in every classroom: Preparing the highly qualified teachers our children deserve. Educational Horizons, 85(2), 111-132.

Davis, F. D. (1989). Perceived usefulness, perceived ease of use, and user acceptance of information technology. MIS quarterly, 319-340.

Dobbs, R. L. (2004). Impact of training on faculty and administrators in an interactive television environment. Quarterly Review of Distance Education, 5(3), 183.

Dogan, S., Pringle, R., \& Mesa, J. (2016). The impacts of professional learning communities on science teachers' knowledge, practice and student learning: A review. Professional development in education, 42(4), 569-588.

Education, A. (2010). Emerge one-to-one laptop learning initiative: Year two report. Alberta Education. School Technology Sector. https://files.eric.ed.gov/fulltext/ED506127.pdf

Garcia, R. C. (2018). The role of information and communication technology in secondary schools (Doctoral dissertation).

Gitomer, D. H., \& Zisk, R. C. (2015). Knowing what teachers know. Review of Research in Education, 39(1), 1-53.

Grossman, P., \& McDonald, M. (2008). Back to the future: Directions for research in teaching and teacher education. American Educational Research Journal, 45(1), 184-205.

Guma, A., Faruque, A. Haolader. \& Khushi, Mohammed. (2013). The role of ICT to make teaching-learning effective in higher institutions of learning in Uganda. International Journal of Innovative Research in Science, Engineering and Technology, 2(8), 4061-4073

Hennessy, S., Harrison, D., \& Wamakote, L. (2010). Teacher factors influencing classroom use of ICT in Sub-Saharan Africa. Itupale Online Journal of African Studies, 2(1), 39-54.

Hill, H. C., Ball, D. L., \& Schilling, S. G. (2008). Unpacking pedagogical content knowledge: Conceptualizing and measuring teachers' topic-specific 
knowledge of students. Journal for Research in Mathematics Education, 372-400.

Hill, H. C., Rowan, B., \& Ball, D. L. (2005). Effects of teachers' mathematical knowledge for teaching on student achievement. American Educational Research Journal, 42(2), 371-406.

Huma, A. (2013). Adaptable program evaluation strategies for teacher education in Pakistan: A reflective paper written on the bases of literature review and document analysis. International Journal of Humanities and Social Sciences, 3(7), 298-305.

International Society for Technology in Education (ISTE) (2008). Essential conditions: Necessary conditions to effectively leverage technology for learning. https://www.iste.org/standards/for-educators

Iqbal, M. N., Ali, M. Q., Hassan, M. U., \& Aalamgeer, M. (2014). Information communication technology in secondary/higher secondary schools in Pakistan: Application and Practices. Journal of Institute of Social Sciences, 1(2), 59-67.

Jamil, M., Jamil, S., \& Rasheed, K. (2017). An assessment of secondary school teachers' performance and skills in ICTs in accordance with National Professional Standards Pakistan. Haripur Journal of Educational Research, 1(1), 62-75.

Jang, S. J. (2019). Exploration of secondary students' creativity by integrating web-based technology into an innovative science curriculum. Computers \& Education, 52(1), 247-255.

Jonassen, D. H. (2000). Computers as mindtools for schools: Engaging critical thinking. Prentice hall.

Kaplan, L. S., \& Owings, W. A. (2013). Culture re-boot: Reinvigorating school culture to improve student outcomes. Corwin Press.

Keengwe, J. (Ed.). (2015). Handbook of research on educational technology integration and active learning. IGI Global.

Khokhar, A. J., \& Javaid, S. (2016). Students and teachers perceptions of ICT use in classroom: Pakistani classrooms. [Paper presentation]. The Asian Conference on Technology in the Classroom. Tokyo.

König, J. (2014). Designing an international instrument to assess teachers'general pedagogical knowledge (GPK): Review of studies, considerations, and recommendations. Technical paper prepared for the OECD Innovative Teaching for Effective Learning (ITEL)-Phase II Project: A Survey to 
Profile the Pedagogical Knowledge in the Teaching Profession (ITEL Teacher Knowledge Survey), Paris, OECD, http://www. oecd. org/officialdocuments/publicdisplaydocumentpdf.

König, J., \& Kramer, C. (2016). Teacher professional knowledge and classroom management: On the relation of general pedagogical knowledge (GPK) and classroom management expertise (CME). ZDM, 48(1-2), 139-151.

König, J., Blömeke, S., Paine, L., Schmidt, W. H., \& Hsieh, F. J. (2011). General pedagogical knowledge of future middle school teachers: On the complex ecology of teacher education in the United States, Germany, and Taiwan. Journal of Teacher Education, 62(2), 188-201.

König, J., Lammerding, S., Nold, G., Rohde, A., Strauß, S., \& Tachtsoglou, S. (2016). Teachers' professional knowledge for teaching English as a foreign language: Assessing the outcomes of teacher education. Journal of Teacher Education, 67(4), 320-337.

Kripanont, N. (2007). Using technology acceptance model of internet usage by academics within Thai Business Schools. [Unpublished PhD Thesis]. Victoria University.

Martin, C. S., Polly, D., Wang, C., Lambert, R. G., \& Pugalee, D. K. (2016). perspectives and practices of elementary teachers using an internet-based formative assessment tool: The case of" assessing mathematics concepts". International Journal for Technology in Mathematics Education, 23(1), 3-11.

Nath, S. (2019). ICT integration in Fiji schools: A case of in-service teachers. Education and Information Technologies, 24(2), 963-972.

Oldfield, A., Broadfoot, P., Sutherland, R., \& Timmis, S. (2012). Assessment in a digital-age: A research review. University of Bristol.

Oye, N. D., Iahad, N. A., \& Rahim, N. A. (2014). The history of UTAUT model and its impact on ICT acceptance and usage by academicians. Education and Information Technologies, 19(1), 251-270.

Policy and Planning Wing. (2009). National professional standards for teachers in Pakistan. Ministry of Education, Government of Pakistan.

Radovanović, D. (2012). Digital divide and social media: Connectivity doesn't end the digital divide, skills do. Scientific American. http://blogs.scientificamerican.com/guest-blog/2011/12/14/digital-divide-a nd-social-media-connectivity-doesnt-end-the-digital-divide-skills-do/

Sadler, P. M., Sonnert, G., Coyle, H. P., Cook-Smith, N., \& Miller, J. L. (2013). The 
influence of teachers' knowledge on student learning in middle school physical science classrooms. American Educational Research Journal, 50(5), 1020-1049.

Sam, D. (2011). Middle school teachers' descriptions of their level of competency in the national education technology standards for teachers. Johnson \& Wales University.

Samaradiwakara, G. D. M. N., \& Gunawardena, C. G. (2014). Comparison of existing technology acceptance theories and models to suggest a well improved theory/model. International Technical Sciences Journal, 1(1), 21-36.

Scherer, R., Siddiq, F., \& Tondeur, J. (2019). The technology acceptance model (TAM): A meta-analytic structural equation modeling approach to explaining teachers' adoption of digital technology in education. Computers \& Education, 128, 13-35.

Shulman, L. L. (1987). A portrait of expertise. Knowledge and Teaching. Foundations of the New Reform, Harvard Educational Review, 57(1), 1-22.

Shulman, L. S. (1986). Those who understand: Knowledge growth in teaching. Educational Researcher, 15(2), 4-14.

Straub, E. T. (2009). Understanding technology adoption: Theory and future directions for informal learning. Review of Educational Research, 79(2), 625-649.

Sweeney, T., West, D., Groessler, A., Haynie, A., Higgs, B. M., Macaulay, J., \& Yeo, M. (2017). Where's the transformation? Unlocking the potential of technology-enhanced assessment. Teaching and Learning Inquiry, 5(1), 1-16.

Venkatesh, V., \& Davis, F. D. (2000). A theoretical extension of the technology acceptance model: Four longitudinal field studies. Management Science, 46(2), 186-204.

Warschauer, M., \& Ware, P. (2008). Learning, change, and power. Handbook of Research on New Literacies, 215-239.

Whitelock, D., \& Watt, S. (2008). Reframing e-assessment:Adopting new media and adapting old frameworks. Learning, Media and Technology, 33(3) https://doi.org/10.1080/17439880802447391

Whitelock, D., Gilbert, L., \& Gale, V. (2011). Technology enhanced assessment and feedback: How is evidence-based literature informing practice? [Paper presentation]. International Computer Assisted Assessment (CAA) Conference, United Kingdom. 


\section{Citation of this Article:}

Aslam, R., Khan, N., \& Ahmed, U. (2020). Technology integration and teachers' professional knowledge with reference to international society for technology in education (ISTE)-standard: A causal study. Journal of Education and Educational Development. 7(2), 307-327. 